\title{
LOS MANUSCRITOS PÓSTUMOS DESDE 1885 EN TRASCRIPCIÓN DIFERENCIADA: VOL. IV
}

- KGW IX: Der handschriftliche Nachlaß ab Frühjahr 1885 in differenzierter Transkription, nach Marie-Luise Haase und Michael Kohlenbach, herausgegeben von Marie-Luise Haase und Martin Stingelin in Verbindung mit der Berlin-Brandenburgischen Akademie der Wissenschaften.

- Vierter Band. Arbeitshefte W I 3, W I 4, W I 5, W I 6, W I 7.

- Bearbeitet von Nicolas Füzesi, Marie-Luise Haase, Thomas Riebe, Beat Röllin, René Stockmar, Jochen Strobel und Franziska Trenkle unter Mitarbeit von Falko Heimer.

- Berlin/New York: Walter de Gruyter, 2004. ISBN 3-11-018093-6.

Si ya en el 2001, en la presentación de la sección novena de $\mathrm{KGW}^{1}$, los encargados de la edición de las obras de Nietzsche sorprendieron a todo el mundo con el anuncio de que el aparato crítico a los fragmentos póstumos a partir de 1885 iba a ser distinto al del resto y que, en lugar del sistema habitual, se había decidido inaugurar una sección en la que se ofrecería, en trascripción diferenciada, todas las anotaciones conservadas de Nietzsche desde la primavera de 1885 hasta enero de 1889, ahora, tres años después, nos vuelven a sorprender con la publicación de KGW IX/4, un nuevo y enorme volumen de cuadernos de Nietzsche. Y decimos enorme más que nada por el formato folio con el que se publica, y que, según se afirma, se va a mantener para los siguientes volúmenes de esta sección en virtud de las características de los cuadernos y carpetas que se van a transcribir en ellos.

Este nuevo volumen contiene la trascripción diferenciada de cinco cuadernos pertenecientes a la serie $\mathrm{W}$, signatura bajo la cual se incluyen los cuadernos redactados durante la llamada época de la transvaloración (Umwerthungszeit), es decir, entre los años 1885 y 1889. De hecho, aquí se transcriben los cuadernos $\mathrm{W} \mathrm{I} 3$ y W I $7^{2}$, que contienen anotaciones fechadas, salvo algunas excepciones,

\footnotetext{
${ }^{1}$ Para un detallado informe sobre los tres primeros volúmenes de esta nueva sección, veáse Parmeggiani, Marco, «Nueva edición de las manuscritos póstumos 1885-1889», Estudios Nietzsche, 2 (2002), 259-261, así como Thüring, Hubert, «Tertium datum: Der 'Nachlaß’ zwischen Leben und Werk. Zur Neuausgabe der handschriftlichen Dokumente des 'späten Nietzsche'», en http://iasl.uni-muenchen.de/rezensio/liste/thuering.html

${ }^{2}$ La signatura de estos cuadernos en el Goethe-Schiller Archiv (GSA), es 71/151, 71/152, $71 / 153,71 / 154$ y $71 / 155$, respectivamente.
} 
entre los meses de mayo y septiembre de 1885 con lo que tanto la interrelación, como la coincidencia temática entre los distintos cuadernos que aquí se publican y el de los transcritos en KGW IX 1-2 $2^{3}$, están más que aseguradas. Estos cinco cuadernos se pueden describir de la siguiente forma:

W I 3 es un cuaderno (16x21) de 136 páginas, escritas de atrás hacia delante y cuya fecha de redacción se sitúa entre los meses de mayo y julio de 1885 , con excepción hecha de las tres primeras páginas (en este caso últimas en lo que a orden de escritura se refiere), en las que hay anotaciones fechadas a principios de 1886. De este cuaderno, Colli-Montinari extrajeron los 84 fragmentos que están bajo la rúbrica 35 y que se encuentran publicados en KGW VII/3 231-270 (= KSA XI 509-548), así como los NF 3[3-5], que corresponden a las anotaciones realizadas en 1886 y que fueron publicadas en KGW VIII/1 171-172 ( = KSA XII 171-172).

W I 4 es la signatura asignada a las 54 páginas que constituyen la parte conservada de un cuaderno (17x21'5) escritas de atrás hacia delante durante los meses de junio y julio de 1885 . De las anotaciones aquí realizadas por Nietzsche, Colli-Montinari extrajeron los 60 fragmentos que constituyen la rúbrica 36 y que fueron publicados en KGW VII/3 273-297 (= KSA XI 549-573). En este cuaderno también se encuentra un fragmento del esbozo de una carta dirigida a Helene Druskowitz, fechada a mediados de agosto de 1885 y que, a falta del original, está publicado en KGB III/3 84.

W I 5 engloba las 48 páginas conservadas de un cuaderno (17x21'5) escrito de atrás hacia delante y que está fechado entre los meses de agosto y septiembre de 1885. De estas páginas Colli-Montinari extrajeron los 16 fragmentos que forman la rúbrica 41 y que se publicaron en KGW VII/3 403-423 (= KSA XI 669-689).

W I 6 es un cuaderno (17x21'5) de 80 páginas, de las que las impares contienen las notas redactadas por Louise Röder-Wiederhold ${ }^{4}$ al dictado de Nietzsche y que el propio filósofo corrigió más tarde, introduciendo también bastantes añadidos. De estas anotaciones, fechadas entre los meses de junio y

\footnotetext{
${ }^{3}$ Véase el cuaderno N VII 1, de donde salen los fragmentos de la rúbrica 34 y que está fechado entre abril y junio de 1885 y las pp. 173-194 del cuaderno N VII 2, que contiene anotaciones fechadas entre agosto y septiembre de 1885 y de donde se extrajeron 21 de los 22 fragmentos de la rúbrica 39. Este período lo completarían las anotaciones contenidas en los folios que se encuentran en las carpetas Mp XVI 1, Mp XVI 2 y Mp XV 2, de donde se extraen los fragmentos de la rúbrica 38, y que están fechadas entre junio y julio de 1885, así como las que se hallan en los folios de Mp XVII 2, de donde Colli-Montinari extrajeron los fragmentos de la rúbrica 42, anotaciones fechadas entre agosto y septiembre de 1885 .

${ }^{4}$ De la mano de esta mujer, amiga de Heinrich Köselitz [Peter Gast] y que estuvo con Nietzsche en Sils-Maria desde el 8 de junio hasta el 6 de julio de 1885 leyéndole en voz alta y escribiéndole al dictado, provienen también las anotaciones realizadas en la carpeta Mp XVI, de donde salen los fragmentos publicados bajo la signatura 38 en KGW VII/3 323-346 (= KSA XI 595-618).
} 
julio de 1885, Colli-Montinari extrajeron los 18 fragmentos que constituyen la rúbrica 37, publicada en KGW VII/3 301-320 (= KSA XI 575-594). De las páginas $1,58,78$ y 79, escritas por el propio Nietzsche en otoño de 1885, se extrajeron los 7 fragmentos que constituyen la rúbrica 45, publicada en KGW VII/3 451-452 (= KSA XI 709-710).

W I 7 es un cuaderno (17x21'5) de 80 páginas escritas de atrás hacia delante fechadas en su gran mayoría entre agosto y septiembre de 1885 . De estas notas Colli-Montinari extrajeron los 70 fragmentos de la rúbrica 40, que están publicados en KGW VII/3 361-400 (= KSA XI 629-668). También en este cuaderno (pp. 1, 5 y 78) se encuentran anotaciones que fueron realizadas a principios de 1886 y que fueron editadas bajo la rúbrica 3[1], 3[2] y 3[16-18] en KGW VIII/1 171 y 175 respectivamente (= KSA XII 171 y 175), así como 7 esbozos de cartas cuya fecha de redacción va desde finales de marzo de 1886 hasta el 4 de febrero de 1888 .

El volumen se complementa con un CD-Rom con los facsímiles de los manuscritos transcritos en KGW IX/4 y con el aparato crítico (Nachbericht), que recoge lo ya publicado en el cd-rom que acompañaba a KGW IX/1-3 y que consta de (1) la descripción de los cuadernos, en la que también se da cuenta de lo escrito por otras personas (los editores del antiguo Nietzsche-Archiv, por ejemplo) que han tenido acceso a ellos; (2) un ilustrativo listado de remisiones (Querverweise), con el que podemos contemplar el 'taller Nietzsche', el proceso de trabajo interno del filósofo, es decir, cómo algunas anotaciones de un cuaderno no son sino copias o reelaboraciones de otras realizadas anteriormente y/o esbozos o versiones preliminares para ulteriores escritos ya sea en otros cuadernos o folios sueltos o incluso para cartas y obras destinadas a la publicación ${ }^{5}$; (3) los comentarios, con significativas modificaciones con respecto a los que sobre las anotaciones de KGW IX/1-3 había en el anterior Nachbericht $^{6}$ y algunas ausencias en la bibliografía ${ }^{7}$; (4) un listado bastante extenso de correcciones (más de 1600), que afectan no únicamente a los fragmentos publicados por Colli-Montinari, sino también a las anotaciones recogidas en KGW VII/4.2 en tanto que versiones preliminares de los mismos; (5) la útil concordancia, ausente en el anterior Nachbericht, entre los fragmentos publicados en Colli-Montinari (KGW y KSA) y la paginación del cuaderno del que se extraen, así como esbozos de cartas (algunos de ellos publicados en KGB ante la ausencia del original) y el lugar que ocupan en los distintos cuadernos; (6) la concordancia inversa, es decir, los distintos cuadernos y los fragmentos

\footnotetext{
${ }^{5}$ Con ello se constata una vez más la íntima, y por otro lado evidente, sensata y lógica relación existente entre las múltiples anotaciones realizadas por Nietzsche durante una misma época.

${ }^{6}$ Aunque se añaden comentarios nuevos y se amplían otros con mayor información, hay que decir también que algunos desaparecen y que, además, es fácilmente observable una notable disminución, o en algunos casos eliminación, de las referencias a otros pasajes de Nietzsche.
} 
póstumos (incluidas versiones preliminares y esbozos de cartas) que de ellos han extraído Colli-Montinari, haciendo también mención del lugar en el que esas anotaciones han sido publicadas con anterioridad, ya sea en la llamada Grossoktavausgabe (GAK para los volúmenes publicados por Koegel y GA para los restantes), en las dos ediciones existentes de La voluntad de poder o bien por Podach en su Ein Blick in Notizbücher Nietzsches (Heidelberg, 1963) y (7) un índice de nombres.

En definitiva, una nueva entrega de los cuadernos de Nietzsche -en unos meses en los que el filósofo, tras publicar en edición privada la cuarta parte de su Así habló Zaratustra vive en Venecia (10 de abril - 6 de junio) y Sils-Maria (7 de junio - mediados de septiembre $)^{8}$ - en los que el lector puede leer en trascripción diferenciada, o si quiere hasta en facsímil, muchas de las anotaciones que servirán como base para la redacción de Más allá del bien y del mal (obra que verá la luz en agosto de 1886) una vez abandonado el proyecto de una segunda edición, totalmente reelaborada, de Humano, demasiado humano.

\section{APÉNDICE}

Tal y como hicimos al final de nuestra concordancia entre La voluntad de poder y la edición Colli-Montinari ${ }^{9}$, ofrecemos aquí la localización de los fragmentos publicados en la tan famosa como discutida compilación dentro de los cuadernos transcritos en KGW IX/4.

$\begin{array}{llll}\S 91 & \text { W I 4, p. 15 (2-34) } & \S 424 & \text { W I 3, p. } 114(8-50) \\ \S 108 & \text { W I 4, p. 12 (24-50) } & \S 443 & \text { W I 4, p. 46 (28-50) } \\ \S 125 & \text { W I 6, pp. 51, 53(2-24) } & \S 463 & \text { W I 3, p. 85 (18-32) } \\ \S 129 & \text { W I 4, p. 14 (24-32) } & \S 464 & \text { W I 6, pp. 59(10-44), 61 (2-36) } \\ \S 132 & \text { W I 3, p. 126(2-44) } & \S 490 & \text { W I 7, p. 52 (2-40) } \\ \S 263 & \text { W I 3, p. 114 (2-6) } & \S 492 & \text { W I 7, p. 66 (2-46) } \\ \S 278 & \text { W I 7, p. 52 (42-50) } & \S 494 & \text { W I 4, p. 30 (12-18) } \\ \S 367 & \text { W I 4, p. 48 (1-24) } & \S 499 & \text { W I 5, p. } 9(24-28) \\ \S 419 & \text { W I 5, pp. 40-41 (2-6) } & \S 502 & \text { W I 7, p. 60 (2-12) } \\ \S 422 & \text { W I 3, pp. 84-85 (2-5) } & \S 512 & \text { W I 7, p. 73 (2-16) }\end{array}$

\footnotetext{
${ }^{7}$ Falta, por ejemplo, la referencia al Journal des Goncourt o a la mayoría de los clásicos latinos que sí aparecían en el anterior Nachbericht.

${ }^{8}$ Esta constituye la cuarta estancia de Nietzsche en Sils-Maria donde, a partir de 1881 y hasta 1888 pasará todos los veranos (con excepción del año 1882). Por lo que a Venecia se refiere, era la tercera primavera que pasaba en esa ciudad (las dos anteriores habían sido en los años 1880 y 1884).

${ }^{9}$ Véase Estudios Nietzsche, 4 (2004), 193-208.
} 


\begin{tabular}{|c|c|}
\hline$\S 520$ & W I 4, p. 31 (18-42) \\
\hline$\S 532$ & W I 7, p. 70 \\
\hline$\S 545$ & W I 4, p. $28(8-22)$ \\
\hline$\S 549$ & W I 4, p. $28(24-30)$ \\
\hline$\S 591$ & W I 3, p. $2(10-12)$ \\
\hline$\S 603$ & W I 3, p. $80(5)$ \\
\hline$\S 618$ & W I 4, p. 24 \\
\hline$\S 619$ & W I 4, p. $26(2-22)$ \\
\hline$\S 630$ & W I 4, p. $30(2-10)$ \\
\hline$\S 637$ & W I 4, p. $30(20-26)$ \\
\hline$\S 642$ & W I 4, p. $31(2-16)$ \\
\hline$\S 645$ & W I 4, p. 29 (2-18) \\
\hline$\S 646$ & W I 4, p. 29 (20-34) \\
\hline$\S 655$ & W I 4, pp. 30 (28-44), $31(44-47)$ \\
\hline$\S 658$ & W I 3, p. $124(4-36)$ \\
\hline$\S 659$ & W I 4, pp. 22 (1-10), 23 \\
\hline$\$ 783$ & W I 7, p. 65 \\
\hline$\S 791$ & W I 5, p. $1(2-21)$ \\
\hline$\S 792$ & W I 4, p. $50(2-26)$ \\
\hline
\end{tabular}

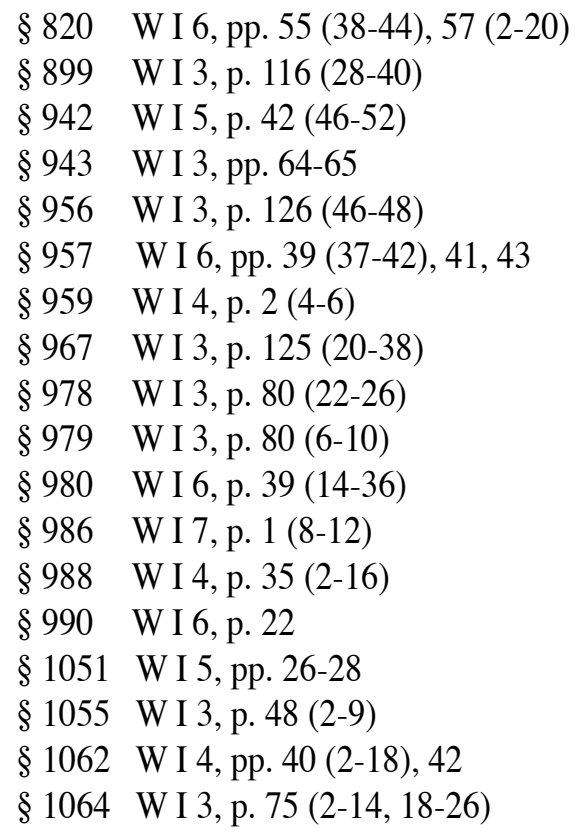

Antonio Morillas

Universidad de Barcelona 
